\title{
RÖKO DIGITAL featured by RKR-RadiologieKongressRuhr - die erfolgreiche digitale Spezialausgabe
}

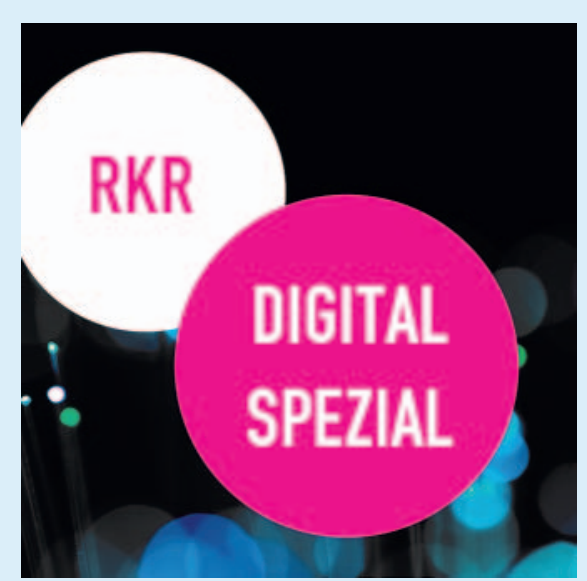

Der RadiologieKongressRuhr (RKR) fand dieses Jahr als kompakte digitale Spezialausgabe eingegliedert in den RÖKO DIGITAL statt. Am 5. November folgten knapp 1200 Teilnehmerinnen und Teilnehmer in 3 Live-Sessions den hervorra- genden Vorträgen der Referierenden und spannenden Diskussionen.

Das Programm bot einen abwechslungsreichen Mix unterschiedlicher Formate und konnte somit eine breite Zuhörerschaft in der Radiologie ansprechen. Neben der Abdomenbildgebung sowie „Fit für den Facharzt“ wurde das Format „Meine schönsten Fehler" als besonderes Highlight bewertet. Anhand aktueller Beispiele und eigener Erfahrungen wurde anschaulich über die Fehlerkultur im klinischen Alltag diskutiert - eine spannende Session, nicht um anzuklagen, sondern um zu lernen und zukünftige Fehler zu vermeiden.

Sollten Sie die spannenden Vorträge der digitalen RKR-Spezialausgabe verpasst haben, können Sie sich die Vorträge (die Anmeldung zum RÖKO DIGITAL und die
DRG-Mitgliedschaft vorausgesetzt) noch bis Ende Januar 2021 auf conrad, der digitalen Lernplattform der DRG, anschauen.

\section{RKR 2021}

Vorbehaltlich der Entwicklung der COVID-19Pandemie hoffen wir, Sie am 4. und 5. November 2021 in Dortmund live begrüßen zu können.

\section{SAVE THE DATE}

14. RadiologieKongressRuhr: 4 . bis 5. November 2021

Mehr Informationen erhalten Sie in den kommenden Monaten hier: www.radiologiekongressruhr.de 